Correspondência | Correspondence:

Secretaria de Estado da Saúde de São Paulo

Av. Dr. Arnaldo, $3511^{\circ}$ andar sala 135

01246-901 São Paulo, SP, Brasil

E-mail: agencia@saude.sp.gov.br

Texto de difusão técnico-científica da

Secretaria de Estado da Saúde de São Paulo.

\section{Tuberculose na população prisional}

\section{Tuberculosis among incarcerated population}

\author{
Divisão de Tuberculose. Centro de Vigilância Epidemiológica \\ "Prof. Alexandre Vranjac". Coordenadoria de Controle de Doen- \\ ças. Secretaria de Estado da Saúde de São Paulo
}

A tuberculose apresenta um potencial de transmissão bastante elevado em instituições fechadas, como presídios, pelas características dessa população. Os indicadores de incidência no Estado de São Paulo atingem cerca de 800 casos por 100.000 detentos, índice várias vezes mais alto do que os 43 por 100.000 da população em geral. Entre a população carcerária feminina, estes valores atingem 1.536 por 100.000 , apesar do menor número absoluto de casos.

Esses aspectos levaram a Secretaria de Estado da Saúde de São Paulo a desenhar um modelo de investigação epidemiológica, dirigido às presidiárias, por intermédio da Divisão de Tuberculose, do Centro de Vigilância Epidemiológica "Professor Alexandre Vranjac" - órgão da Coordenadoria de Controle de Doenças (CCD). Essa população, por ter menor contingente em relação ao grupo de detentos do sexo masculino, permitiu uma abordagem mais rápida, podendo ser reproduzida para os detentos, posteriormente.

Tendo em vista que a investigação terá a conotação de modelo, dela farão parte os profissionais do sistema prisional que têm contato direto com as presidiárias. Para o início do trabalho foi escolhida a Penitenciária Feminina da Capital, com 639 presidiárias e cerca de 100 profissionais.

Participaram do preparo da estratégia, além da Divisão de Tuberculose, representantes do Programa de Controle de Doenças Sexualmente Transmissíveis e Aids (DST/Aids), da Secretaria da Administração Pe- nitenciária, por meio de sua Coordenadoria de Saúde, da Secretaria Municipal de Saúde da Capital, por meio dos programas de Tuberculose e de DST/Aids e, da Regional de Saúde Norte (SUVIS Santana) e Centro de Testagem e Aconselhamento de Pirituba.

Durante o período de 2 a 7 de março de 2006, 529 presidiárias e 36 profissionais receberam informações sobre tuberculose. Na mesma fase, realizou-se interrogatório com todas as presidiárias e profissionais sobre ocorrência de tosse por mais de duas semanas, caracterizando os sintomas de tuberculose. Para essas sintomáticas, foi realizada coleta de escarro e exame radiológico. Ao mesmo tempo, foi oferecido o teste sorológico para HIV, hepatite e sífilis para toda a população da instituição.

Foram identificadas preliminarmente 108 sintomáticas respiratórias. Foram realizadas 82 coletas de escarro para baciloscopia, cultura e teste de sensibilidade, além de 100 exames radiológicos e 140 amostras para teste do HIV, da hepatite e da sífilis. Foram identificados dois novos casos de tuberculose e confirmados sete que já estavam em tratamento.

Mesmo em fase inicial, a estratégia do programa pode ser avaliada como adequada, embora ainda devam ser feitos ajustes na operacionalização. Mediante esses dados iniciais, é possível confirmar a gravidade do quadro da tuberculose entre a população prisional feminina, tendo sido constatados nove casos de tuberculose num total de 639 . 